11 McGuire A, Henderson J, Mooney G. Cost benefit approach in theory. In The economics of health care. London: Routledge and Kegan Paul, 1988: 74-101

12 Goodman CM, Busuttil A, Chisholm GD. Age and size and grade of tumour predict prognosis in incidentally diagnosed carcinoma of the prostate Br F Urol 1988;62:576-80.

13 Hăkansson $\mathrm{S}$, Jonsson E. Screening for cancer-underlaget dåligt för kalkyl om kostnader och nytta. Lakartidningen 1984;81:4734-42.

14 Esposti P-L. Aspiration biopsy and cytological evaluation for primary diagnosis and follow-up. In: Jacobi GH, Hohenfellner R, eds, Prostute cancer. Baltimore: Williams and Wilkins, 1982:71-93.

15 Lundberg S, Berge T. Prostatic carcinoma. An autopsy study. Scand f Urol

16 Madsen PO, Graversen PH, Gasser TC, et al. Treatment of localised prostatic cancer. Radical prostatectomy versus placebo. A 15 year follow-up. Scand 7 Urol Nephrol 1988;suppl 110:95-100.

\title{
Is intrauterine growth retardation with normal umbilical artery blood flow a benign condition?
}

\author{
Gerard Burke, Bernard Stuart, Patricia Crowley, Siobhán Ní Scanaill, John Drumm
}

\begin{abstract}
Objective-To determine whether intrauterine growth retardation associated with normal umbilical artery blood flow is a benign condition.

Design-A prospective comparative study of growth retarded fetuses with normal and abnormal umbilical artery blood flow.

Setting-The fetal assessment clinic of a large maternity hospital in Ireland.

Patients - 179 Women with singleton pregnancies in which the fetal abdominal circumference, measured by ultrasonography, was below the fifth centile for gestation.

Main outcome measures-Perinatal deaths, fetal distress requiring caesarean section, preterm delivery, cerebral irritation.

Results-Of 124 fetuses with normal flow, all physically normal fetuses survived but one baby had cerebral irritation; there were six preterm deliveries and four caesarean sections for fetal distress. Among 55 women with physically normal fetuses with abnormal flow there were two midtrimester abortions, three perinatal deaths, and one case of cerebral irritation; there were 23 preterm deliveries and six caesarean sections for fetal distress in labour.

Conclusions-Intrauterine growth retardation associated with normal umbilical blood flow is a different entity from that associated with abnormal flow, normal flow being largely benign and abnormal flow carrying a serious risk of adverse outcome.
\end{abstract}

\section{Introduction}

Intrauterine growth retardation is an important cause of perinatal death. In the Republic of Ireland the death rate in late pregnancy of normal fetuses weighing between 2000 and $2499 \mathrm{~g}$ was $37 \cdot 2$ and $39 \cdot 7$ per 1000 in 1986 and 1987 respectively. ${ }^{1}$ Babies of this birth weight accounted for only $2 \cdot 7 \%$ of total births but for $27 \cdot 6 \%$ of the deaths of normal fetuses in late pregnancy. No reliable method exists to establish whether a fetus is small because of placental insufficiency or because of genetic and racial factors, when it is small but appro-

Coombe Lying-In Hospital, Dublin 8, Ireland

Gerard Burke, MRCOG, research registrar

Bernard Stuart, FRCOG, consultant

Patricia Crowley, MrCoG, senior lecturer

Siobhán Ní Scanaill, RM, ultrasonographer

John Drumm, FRCOG, master

Correspondence to:

Dr Burke. growth retarded. Consequently, women with small but healthy fetuses may be admitted to hospital unnecessarily and have unneeded intervention, including caesarean section.

Intrauterine growth retardation associated with normal umbilical artery blood flow has been suggested to be a largely benign condition. ${ }^{2}$ A recent report suggested that Doppler studies of the umbilical artery can identify a group of growth retarded babies at increased risk of intrapartum hypoxia. ${ }^{3}$ Cordocentesis has shown a significant negative correlation between the severity of fetal hypoxia and the mean velocity of blood in the fetal aorta. ${ }^{+}$In addition, although no correlation has been found between the size of the fetus and hypoxia or acidosis, absence of end diastolic blood flow seemed to be a good marker of asphyxia in growth retarded fetuses.

We tested the hypothesis that intrauterine growth retardation associated with normal patterns of umbilical artery blood flow is largely benign.

\section{Patients and methods}

All high risk patients referred to the fetal assessment clinic at this hospital from September 1988 to May 1989 were entered into the study. Each woman had fetal biometry, and the biophysical profile of the fetus was scored. ${ }^{6}$ Suspected intrauterine growth retardation was the commonest indication for referral to the clinic. Growth retardation was diagnosed if the fetal abdominal circumference, measured by ultrasonography, was below the fifth centile for gestation. ${ }^{7}$ All women underwent velocity waveform analysis of the umbilical artery by continuous wave Doppler ultrasound at each visit to the clinic. The equipment consisted of a real time ultrasound scanner (General Electric RT 3600) and a spectrum analyser (Doptek 9012) which has a high pass filter of $150 \mathrm{~Hz}$. Informed consent was obtained from each patient, and ethical approval was granted by the hospital.

Results of the Doppler investigation were withheld from the doctors managing the cases. We calculated the peak systolic to end diastolic ratio for each fetus and identified three blood flow patterns: in type 1 the ratio was $\leqslant 2$ SD above the mean for gestational age ${ }^{8}$; in type 2 the ratio was $>2$ SD above the mean; and in type 3 end diastolic blood flow was absent or reversed.

Birthweight centiles for gestation were based on standards for Irish neonates ${ }^{9}$ and were not applied to babies born before 34 weeks' gestation as no reliable data were available. A perinatal death was defined as a stillborn fetus weighing $\geqslant 500 \mathrm{~g}$ or the death within seven days of birth of a neonate who weighed $\geqslant 500 \mathrm{~g}$ at birth. Cerebral irritation was defined as convulsions, abnormal reflexes, or abnormal tone in the first seven days after birth. ${ }^{10}$

We calculated relative risks and $95 \%$ confidence intervals according to the method of Morris and Gardner. ${ }^{11} \chi^{2}$ Tests, with correction for continuity, were performed for discrete variables.

\section{Results}

At the final assessment 179 fetuses had an abdominal circumference below the fifth centile. Of these, 124 had normal umbilical artery velocity waveforms. Forty four fetuses had type 2 flow and 11 had type 3 . Table I shows the outcome of pregnancy according to the type of umbilical artery blood flow. In the group with type 3 flow there were two midtrimester abortions: one fetus was born alive but weighed less than $500 \mathrm{~g}$ and could not be resuscitated. Of the 166 babies born after 34 


\begin{tabular}{|c|c|c|c|c|}
\hline & $\begin{array}{l}\text { Type } 1- \\
\text { systolic:diastolic } \\
\text { ratio } \leqslant 2 \text { SD } \\
\text { above mean for } \\
\text { gestation } \\
(\mathrm{n}=124)\end{array}$ & $\begin{array}{c}\text { Type 2- } \\
\text { systolic:diastolic } \\
\text { ratio }>2 \text { SD } \\
\text { above mean for } \\
\text { gestation } \\
(n=44)\end{array}$ & $\begin{array}{c}\text { Type 3- } \\
\text { no end diastolic } \\
\text { blood flow } \\
(n=11)\end{array}$ & $\begin{array}{c}\text { Total } \\
(\mathrm{n}=179)\end{array}$ \\
\hline Midtrimester abortions & & & $2(18)^{\star \star \star} \dagger$ & $2(1)$ \\
\hline Stillbirths: & & & & \\
\hline Total & & $3(7)$ & $2(18)^{\star \star \star}$ & $5(3)$ \\
\hline Congenital anomaly & & $2(5)$ & & $2(1)$ \\
\hline \multicolumn{5}{|l|}{ Neonatal deaths: } \\
\hline Total & $4(3)$ & $1(2)$ & & $5(3)$ \\
\hline Congenital anomaly & $4(3)$ & $1(2)$ & & $5(3)$ \\
\hline Major congenital anomaly & $5(4)$ & $5(11)$ & & $10(6)$ \\
\hline Cerebral irritation & $1(1)$ & $1(2)$ & & $2(1)$ \\
\hline Baby born before 37 weeks' gestation & $6(5)$ & $14(32)^{\star \star \star}$ & $9(82)^{\star \star \star}$ & $29(16)$ \\
\hline Baby born before 34 weeks' gestation & $2(2)$ & $3(7)$ & $8(73)^{\star \star \star}$ & $13(7)$ \\
\hline Baby admitted directly to neonatal intensive care unitł & $25(20)$ & $22(56)^{\star \star \star \star}$ & $6(75)^{\star \star \star}$ & $53(31)$ \\
\hline Induction of labour $\neq$ & $65(52)$ & $16(41)$ & $1(13)$ & $82(48)$ \\
\hline Elective caesarean section $\ddagger$ & $19(15)$ & $15(38)$ & $7(88)^{\star}$ & $41(24)$ \\
\hline Emergency caesarean section for fetal distress in labour $\ddagger$ & $4(3)$ & $5(13) \star$ & $1(13)^{\star}$ & $10(6)$ \\
\hline
\end{tabular}

${ }^{\star} \mathrm{p}<0 \cdot 05,{ }^{\star \star} \mathrm{p}<0 \cdot 01,{ }^{\star \star \star} \mathrm{p}<0 \cdot 001$ Compared with group with type 1 flow.

TABLE II-Incidence (per 1000 fetuses) of adverse outcome with normal and abnormal umbilical artery blood flow

\begin{tabular}{|c|c|c|c|}
\hline Outcome & $\begin{array}{l}\text { Normal flow } \\
(n=124)\end{array}$ & $\begin{array}{l}\text { Abnormal flow } \\
(\mathbf{n}=55)\end{array}$ & $\begin{array}{c}\text { Relative risk } \\
\text { (95\% confidence } \\
\text { interval) }\end{array}$ \\
\hline Midtrimester abortion & & $36 \cdot 4$ & \\
\hline Perinatal death & $32 \cdot 3$ & $109 \cdot 1$ & $3.4(1.0$ to 11.5$)$ \\
\hline Midtrimester abortion and perinatal death & $32 \cdot 3$ & $145 \cdot 5$ & $4 \cdot 5(1.4$ to $14 \cdot 3)$ \\
\hline Perinatal death (corrected for major congenital anomålies) & & $54 \cdot 5$ & \\
\hline Cerebral irritation & $8 \cdot 1$ & $18 \cdot 2$ & $2 \cdot 3(0 \cdot 1$ to $36 \cdot 1)$ \\
\hline Preterm delivery & 48 & $418 \cdot 0$ & $12 \cdot 2(5 \cdot 2$ to $28 \cdot 4)$ \\
\hline $\begin{array}{l}\text { Emergency caesarean section for fetal distress (excluding } \\
\text { stillbirths and elective caesarean sections) }\end{array}$ & 38 & 222 & $7 \cdot 2(2 \cdot 2$ to $23 \cdot 8)$ \\
\hline
\end{tabular}

weeks' gestation, 63 of the 122 with normal flow and 33 of the 44 with abnormal flow had a birth weight below the fifth centile $(p<0 \cdot 05)$.

Table II gives the relative risks of each outcome for abnormal flow (types 2 and 3) compared with normal flow (type 1).

\section{Discussion}

Only one unfavourable outcome, cerebral irritation in a baby with a symmetric growth pattern, occurred among the 119 physically normal fetuses with retarded growth and normal umbilical artery waveforms. In the group with normal blood flow only one normal baby was delivered before 34 weeks' gestation and the incidence of fetal distress requiring emergency caesarean section ( 38 per 1000 births) was fairly low. On the other hand, intrauterine growth retardation accompanied by abnormal waveforms was associated with high perinatal mortality (both uncorrected (109.1 per 1000 fetuses) and corrected (54.5 per 1000) for congenital abnormalities) and a high rate of midtrimester abortion $(36.4$ per 1000$)$. Abnormal flow also conferred a relative risk of seven for fetal distress requiring caesarean section and of 12 for preterm delivery. The increased incidence of adverse outcome was not confined to fetuses with no end diastolic blood flow, being found also in those with high peak systolic to end diastolic ratios (type 2 flow).

Data from the metropolitan Atlanta congenital defects programme showed that the risk of a major defect being diagnosed in the first year of life increases from $3.3 \%$ for infants who did not have intrauterine growth retardation to $8.0 \%$ for infants who do..$^{12}$ Fetuses with major abnormalities have an increased incidence of abnormal umbilical artery velocity waveforms. ${ }^{13}$ We found an increased incidence of major congenital malformation in fetuses with intrauterine growth retardation whether the patterns of blood flow were normal (4\%) or abnormal (9\%), and this contributed to perinatal mortality in both groups.
When abnormal flow is defined as the absence of end diastolic flow Doppler analysis has a high specificity $(95 \%)$ when used as a secondary diagnostic test for growth retardation suspected after routine fetometry. ${ }^{14}$ The broader definition of abnormal flow that we used seemed to improve the sensitivity for detecting fetal compromise; several fetuses that were compromised had type 2 flow. In addition, the positive predictive value of the fetal abdominal circumference for a birth weight below the fifth centile for gestation is increased from $52 \%$ to $75 \%$ when umbilical artery blood flow is abnormal.

To our knowledge we are the first to show that intrauterine growth retardation associated with normal umbilical artery velocity waveforms is largely benign in physically normal fetuses. Intervention rates, however, were high whether fetuses had normal or abnormal flow, and this indicates the seriousness with which intrauterine growth retardation is regarded by obstetricians. We cannot determine how these high intervention rates contributed to the favourable results in the group with normal blood flow, but more conservative management could probably be safely implemented in this group; further studies are required to determine this.

1 Clinch J. Perinatal mortality 1986 and 1987. Ir F Med Sci 1989;158:148-9. 2 Redman CR. Examination of the placental circulation by Doppler ultrasound. BrMed f 1989;298:621-2.

3 Dempster J, Mires GJ, Patel N, Taylor DJ. Umbilical artery velocity waveforms: poor association with small-for-gestational-age babies. waveforms: poor association
Brf Obstet Gynaecol 1989;96:692-6.

4 Soothill PW, Nicolaides KH, Bilardo CM, Campbell S. Relationship of fetal hypoxia in growth retardation to mean blood velocity in the fetal aorta. Lancet 1986;ii:1118-20.

5 Nicolaides KH, Bilardo CM, Soothill PW, Campbell S. Absence of enddiastolic frequencies in the umbilical artery: a sign of fetal hypoxia an acidosis. Br Med f 1988;297:1026-7.

6 Manning F, Morrison I, Lange IR, Harman CR, Chamberlain PF. Fetal assessment based on fetal biophysical profile scoring experience in 12,620 referred high-risk pregnancies. Am $\mathcal{f}$ Obstet Gynecol 1985;151:343-50.

7 Hadlock FP, Deter RL, Harrist RB, Park SK. Fetal abdominal circumference as a predictor of menstrual age. $A f R$ 1982;139:367-70.

8 Stuart B, Drumm J, FitzGerald DE, Duignan NM. Fetal blood velocity waveforms in normal pregnancy. Br $\mathcal{O}$ Obstet Gynaecol 1980;87:780-5.

9 Hayes A, Daly L, O'Brien NG, McDonald D. Anthropometric standards for Irish newborn. Ir Med f 1983;76:60-70.

10 Prechtl HF, Beintema D. The neurological examination of the full term newbor Prechtl HF, Beintema D. The neurological examination of the full term new
infant. London: Heinemann Medical for Spastics International, 1964.

11 Morris JA, Gardner MJ. Calculating confidence intervals for relative risks (odds ratios) and standardised ratios and rates. Br Med f 1988;296:1313-6.

12 Khoury MJ, Erickson JD, Cordero JF, McCarthy BJ. Congenital malformation and intrauterine growth retardation: a population study. Pediatric $1987 ; 82: 83-90$

13 Trudinger BJ, Cook CM. Umbilical and uterine artery flow velocity waveforms associated with major fetal abnormality. Br $\mathcal{F}$ Obstet Gynaecol 1985;92: 666-70.

14 Marsal K, Persson PH. Ultrasonic measurement of fetal velocity waveforms as a secondary diagnostic test in screening for intrauterine growth retardation. Journal of Clinical Ultrasound 1988;16:239-44.

(Accepted 6 February 1990) 